\title{
Solution-Based Evolution and Enhanced Methanol Oxidation Activity of Monodisperse Platinum-Copper Nanocubes**
}

\author{
Dan Xu, Zhaoping Liu, Hongzhou Yang, Qingsheng Liu, Jun Zhang, Jiye Fang,* \\ Shouzhong Zou, * and Kai Sun
}

Platinum nanoparticles (Pt NPs) have been extensively studied because of their unique catalytic properties in various significant applications. ${ }^{[1-8]}$ It has been shown that the catalytic activity of Pt NPs is highly dependent on the surface atomic arrangements of the particles. ${ }^{[9-11]}$ For example, previous studies on oxygen reduction in adsorbing acidic solutions show that $\mathrm{Pt}\{100\}$ planes are more active than $\mathrm{Pt}$ $\{111\}$ planes, ${ }^{[12,13]}$ and the current density measured on $\mathrm{Pt}$ nanocubes is higher than that of truncated cubic Pt nanocrystals (NCs). ${ }^{[14]} \mathrm{Pt}$ nanocubes ${ }^{[15-17]}$ have therefore received more attention as electrocatalysts than other morphologies such as multipods ${ }^{[18,19]}$ and one-dimensional nanostructures. ${ }^{[20,21]}$ To further reduce the overall use of expensive $\mathrm{Pt}$ and afford the potential of poisoning resistance, platinumbased bimetallic NCs such as $\mathrm{Pt}-\mathrm{Ni},{ }^{[22,23]} \mathrm{Pt}-\mathrm{Co},{ }^{[24-28]}$ and $\mathrm{Pt}-$ $\mathrm{Cu}^{[29-32]}$ have attracted increasing interest. Moreover, recent reports indicate that electrocatalytic activities of some platinum-containing bimetallic NCs are superior to those of pure Pt metal. ${ }^{[25-28]}$ Therefore, the synthesis of platinumcontaining nanocubes and the examination of their electrocatalytic performance is a highly worthwhile and significant step. However, to the best of our knowledge, there have been

[*] D. Xu, ${ }^{[+]}$J. Zhang, Prof. Dr. J. Fang

Department of Chemistry

State University of New York at Binghamton

Binghamton, NY 13902 (USA)

Fax: (+ 1) 607-777-4478

E-mail: jfang@binghamton.edu

Homepage: http://chem.binghamton.edu/FANG

Dr. H. Yang, Prof. Dr. S. Zou

Department of Chemistry and Biochemistry, Miami University

Oxford, OH 45056 (USA)

E-mail: zous@muohio.edu

Dr. Z. Liu ${ }^{[+]}$

Ningbo Institute of Materials Technology and Engineering

Chinese Academy of Sciences

Ningbo, Zhejiang 315211 (P. R. China)

Dr. Q. Liu

Department of Chemistry, Texas A\&M University

College Station, TX 77842 (USA)

Dr. K. Sun

Department of Materials Science and Engineering University of Michigan, Ann Arbor, MI 48109 (USA)

$\left.{ }^{+}\right]$These authors contributed equally to this work.

$[* *$ This work was partially supported by the NSF (DMR-0731382 \& CHM-0616436), DOE (DE-FG02-07ER86296), and the Research Foundation of SUNY. We thank Dr. Jibao He and Dr. Amar Kumbhar for their assistance with the TEM studies.

Supporting information for this article is available on the WWWW under http://dx.doi.org/10.1002/anie.200900293. very few reports on the preparation of platinum-containing bimetallic nanocubes and the investigation of their electrocatalytic behavior to date. Herein, we report a convenient and effective colloidal method for the synthesis of high-quality Pt$\mathrm{Cu}$ nanocubes and their electrocatalytic activity towards methanol oxidation. The influences of several important experimental parameters on the final product development were also explored through systematic studies on the growth of $\mathrm{Pt}-\mathrm{Cu}$ nanocubes.

The $\mathrm{Pt}-\mathrm{Cu}$ nanocubes were prepared by simultaneous reduction of a 1:1 molar ratio of platinum(II) acetylacetonate $\left(\left[\mathrm{Pd}(\mathrm{acac})_{2}\right]\right)$ and copper(II) acetylacetonate $\left(\left[\mathrm{Cu}(\mathrm{acac})_{2}\right]\right)$ by 1,2-tetradecanediol (TDD) in 1-octadecene (ODE) as solvent, which also contained tetraoctylammonium bromide (TOAB), oleylamine (OLA), and a trace amount of 1dodecanethiol (DDT). A typical transmission electron microscopic (TEM) image shows that the overall morphology of the sample consists of $(8.0 \pm 1.0) \mathrm{nm}$ (side length) $\mathrm{Pt}-\mathrm{Cu}$ nanocubes, which are formed in greater than $90 \%$ selectivity (Figure 1a). The nanocube composition has been extensively investigated by using various techniques including inductively coupled plasma mass spectrometry (ICP-MS) and energydispersive X-ray spectroscopy equipped on a TEM (EDSTEM) ${ }^{[33]}$ and the consistent results obtained suggest that the $\mathrm{Pt} / \mathrm{Cu}$ molar ratio is $3: 2$. A TEM diffraction pattern of the Pt$\mathrm{Cu}$ nanocubes (Figure $1 \mathrm{~b}$ ) indicates a high crystallinity of these NCs and a $\{200\}$-enhanced diffraction (see below). The high-resolution TEM (HRTEM) image of a single Pt-Cu nanocube (Figure 1c) shows clear lattice fringes with an interfringe distance of approximately $1.90 \AA$, which corre-

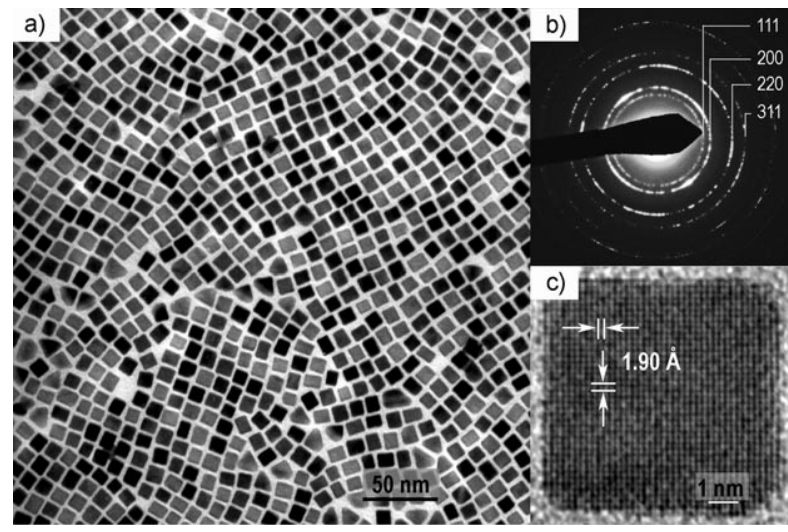

Figure 1. a) Low magnification TEM image of the overall morphology of $\mathrm{Pt}-\mathrm{Cu}$ nanocubes. b) TEM selected-area electron diffraction pattern of the Pt-Cu nanocubes. c) High-resolution TEM image of a selected Pt-Cu nanocube. 
sponds to the lattice spacing of the $\mathrm{Pt}-\mathrm{Cu}\{200\}$ planes. A powder XRD pattern of the $\mathrm{Pt}-\mathrm{Cu}$ nanocubes deposited on a normal sample holder (Figure 2) displays typical peaks that

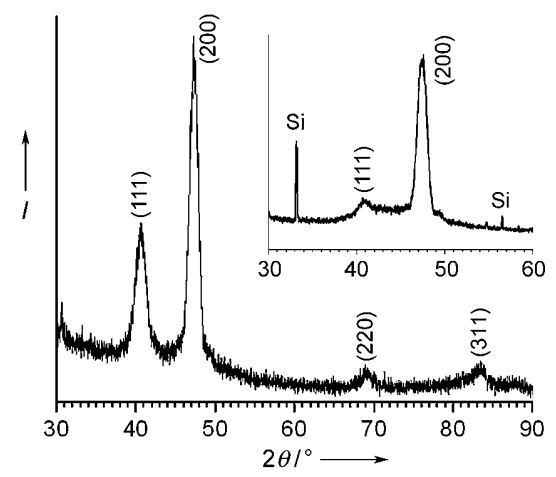

Figure 2. Powder X-ray diffraction (XRD) pattern of the Pt-Cu nanocubes. The inset XRD pattern was recorded from a self-assembled thin film of Pt-Cu nanocubes on a polished silicon wafer and shows the (100) texture.

are in agreement with those of a standard $\mathrm{PtCu}$ pattern (refer to JCPDS ICDD card 48-1549). No single-component peak from either $\mathrm{Pt}$ or $\mathrm{Cu}$ was detected, thus confirming the presence of only single-phase $\mathrm{PtCu}$ alloy. Note that, as shown in Figure 2, the relative intensity of the (200) diffraction peak is much stronger than that of the (111) peak, with an approximate ratio of 240:100. This signal, when compared to the face-centered cubic (fcc) $\mathrm{PtCu}$ alloy pattern with a ratio of 65:100 (JCPDS ICDD card 48-1549), indicates that the NC pattern was (100) textured. Assembly of these nanocubes apparently results in a further enhancement of the (200) peak (Figure 2, inset); in this case the sample suspension was deposited on a polished $<100\rangle$ silicon wafer prior to the XRD measurement. As discussed previously, ${ }^{[34]}$ this observation suggests the existence of a $\mathrm{Pt}-\mathrm{Cu}$ nanocube layer, thus further verifying the dominance of cubic $\mathrm{Pt}-\mathrm{Cu}$ in the product.

Among all the experimental parameters, the amount of TOAB appears to be the key for successful nanocube preparation. In the absence of TOAB, only faceted polyhedral NPs with a broad size distribution are produced (Figure S1a in the Supporting Information). Addition of TOAB (0.3 mmol) into the typical system (see the Experimental section) results in polyhedral NPs that are much less shape-controlled and contain around $40 \%$ cubelike NPs with a size range of 2.5 to $7.8 \mathrm{~nm}$ (Figure S1b in the Supporting Information). If the amount of TOAB is increased to $1.0 \mathrm{mmol}$, the final products are composed of aggregated octapods and tetrahedra with a size range of 20 to $30 \mathrm{~nm}$ (Figure S1c in the Supporting Information). TOAB therefore plays the most important role in controlling the size of the $\mathrm{Pt}-\mathrm{Cu}$ nanocubes. We propose that the $\mathrm{Br}^{-}$ions from TOAB effectively stabilize the $\{100\}$ faces of the $\mathrm{Pt}-\mathrm{Cu} \mathrm{NCs}$; this stabilization lowers the total surface energy of the $\{100\}$ faces and induces the evolution of nanocubes. This function of $\mathrm{Br}^{-}$ions in metallic nanocube evolution has been elucidated previously. ${ }^{[35-37]}$ The effectiveness of TOAB can be further confirmed by replacing TOAB with the same amount of cetyltrimethylammonium bromide (CTAB), although use of the latter leads to a slight degradation of the product quality. $\mathrm{Pt}-\mathrm{Cu} \mathrm{NCs}$ synthesized using CTAB exhibit the following characteristics: they have a lower proportion of nanocubes mixed with nanotetrahedra, they are easily aggregated, and contain a considerable amount of small NPs with a size of less than $2 \mathrm{~nm}$ (Figure S2 in the Supporting Information). This relatively low quality possibly results from the low compatibility of CTAB with the solvent used. It was realized that OLA plays another significant but different role. Without OLA, NCs with a high degree of aggregation were formed (Figure S3a in the Supporting Information), which indicated that OLA is indispensable for the stabilization of the colloidal NCs. If too much of OLA (e.g., $1.8 \mathrm{mmol}$ ) was used, however, aggregated NCs with enlarged sizes were produced (Figure S3b in the Supporting Information), which suggests that less $\mathrm{Pt}$ is released for the nucleation because of the stronger binding of OLA. ${ }^{[38,39]} \mathrm{We}$ therefore infer that an appropriate amount of OLA is essential to tentatively stabilize the clusters of $\mathrm{Pt}$ as well as $\mathrm{Cu}$ in the initial stage of the reaction, and that the growth of $\mathrm{Pt}-\mathrm{Cu}$ nanocubes is synergistically controlled by both OLA and TOAB. In order to harvest high-quality $\mathrm{Pt}-\mathrm{Cu}$ nanocubes, the ratio of OLA/TOAB was optimized in the range from 1.5 to 2.0 .

In addition to the cooperative effect of TOAB and OLA, the morphology of the NCs is also strongly affected by DDT, the presence of which can fine-tune the reduction rate between $\mathrm{Pt}^{\mathrm{II}}$ and $\mathrm{Cu}^{\mathrm{II}}$. In the absence of DDT, most of Pt$\mathrm{Cu}$ NCs produced are $1-3 \mathrm{~nm}$ in size and irregular in shape, with a mixture of a few $\mathrm{Pt}-\mathrm{Cu}$ nanocubes that are approximately $4 \mathrm{~nm}$ in size (Figure S4a in the Supporting Information). Under the typical experimental conditions, only $0.05 \mathrm{mmol}$ of DDT was required to generate ideal $\mathrm{Pt}-\mathrm{Cu}$ nanocubes. An excess of DDT (e.g., $0.075 \mathrm{mmol}$ ) results in the growth of some partially filled nano-octapods $(>60 \%)$ with a size of 13-19 nm, and some flowerlike NCs (Figure S4b in the Supporting Information). We have specifically examined the decomposition temperature of a single $\mathrm{Cu}$ or $\mathrm{Pt}$ precursor in the same system. Without DDT, $\mathrm{Pt}$, or $\mathrm{Cu}$, the precursors start to decompose at 180 or $230^{\circ} \mathrm{C}$, respectively, in comparison with the initial decomposition temperature of approximately $215^{\circ} \mathrm{C}$ in a typical $\mathrm{Pt}-\mathrm{Cu}$ alloy synthesis. It is concluded that DDT acts as a co-reduction agent that accelerates the reduction rate of $\mathrm{Cu}^{\mathrm{II}}$ and reduces that of $\mathrm{Pt}^{\mathrm{II}}$. As a mild reducing agent, TDD can facilitate the nucleation process and is also necessary for the formation of $\mathrm{Pt}-\mathrm{Cu}$ nanocubes with uniform sizes. In the absence of TDD, the NCs were formed as partially filled octapods with sizes of 10-13 nm (Figure S5a in the Supporting Information). Once a small amount of TDD was introduced, the particle size significantly decreased. For instance, the size of $\mathrm{Pt}-\mathrm{Cu}$ nanocubes prepared with $1.0 \mathrm{mmol}$ TDD could be reduced to $5-10 \mathrm{~nm}$ (Figure S5b in the Supporting Information).

To explore the nanocube growth mechanism, we systematically analyzed the intermediate with a precise tuning of the relative amounts of TDD and DDT. In a typical synthesis, the reaction (with $0.5 \mathrm{mmol} \mathrm{TDD}$ and $0.05 \mathrm{mmol} \mathrm{DDT}$ ) proceeded too fast to trap the intermediates. When the amounts 
of TDD and DDT were varied to 0.25 and $0.07 \mathrm{mmol}$ respectively, it was possible to extract the intermediate NCs successfully once the system temperature approached $223^{\circ} \mathrm{C}$ A TEM image of the instantaneously formed product is shown in Figure $3 \mathrm{a}$. This product is believed to be the

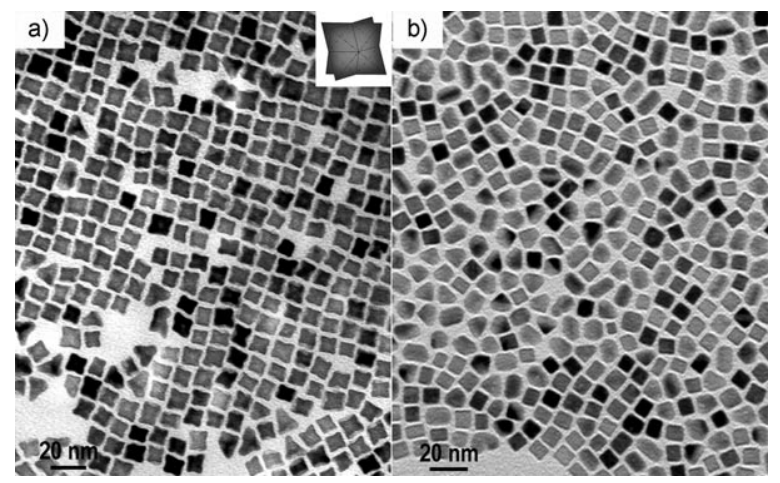

Figure 3. TEM images of intermediate products collected in a typical synthesis under specified conditions. a) During the solution color change from light-yellow to dark-brown while the system temperature reached $223^{\circ} \mathrm{C}(0.25 \mathrm{mmol}$ TDD, $0.07 \mathrm{mmol}$ DDT) and b) after $4 \mathrm{~min}$ of reaction at $230^{\circ} \mathrm{C}$.

intermediate that is formed while the nucleating seeds were converting to nanocubes, as indicated by a rapid color change of the solution from light-yellow to dark-brown at this crucial point. As shown, most of the NCs (>90\%) are octapods with an average size of 6-8 $\mathrm{nm}$, and some are tetrahedra with a side length of $7-8 \mathrm{~nm}$. It is believed that the evolution process consists of a nucleation stage and a further Ostwald ripening growth.$^{[40,41]}$ In the short nucleation stage, a kinetic equilibrium, which arises from the supersaturation of the precursors and results in a rapid deposition of metallic clusters into seeds, may be the key driving force for the NC growth. ${ }^{[42]}$ It has also been reported that the $\{100\}$ crystallographic facets for an fcc structure generally possess higher surface energy than the $\{111\}$ facets. ${ }^{[43,44]}$ Studies on bulk PtCu indicate that the $\{100\}$ faces are of higher surface energy because of atomic interdiffusion as well as $\mathrm{Cu}$ segregation on $\{100\} .{ }^{[45]}$ These factors result in an anisotropic growth, which makes the crystal growth rate in the $<100>$ direction much faster than that in other directions. In order to minimize the total surface energy, the tiny seeds have to be developed as nano-octapods or nanotetrahedra that are bounded by $\{111\}$ low-surfaceenergy facets, whereas the $\{100\}$ planes are rapidly eliminated. When the seeds are completely generated, the difference of total surface energy on each crystal surface will thermodynamically dominate the shape evolution because of the existence of well-developed crystal facets and the consumption of feedstock. As discussed above, the order of the total surface energy of various crystallographic facets in solution may be altered by varying the composition of mixed capping ligands, as the binding capability of each capping ligand on various crystal facets may not be the same (for example, the bromide ion of TOAB can selectively stabilize the $\{100\}$ facets). With an appropriate tuning of the ligand composition, the $\{100\}$ facets can have the lowest surface energy and remain as the terminal planes of NCs. In this case, it will be energetically favorable for the spaces between the octapod branches to be filled by the further-reduced $\mathrm{Pt}$ and $\mathrm{Cu}$ atoms, and the particles will eventually develop into nanocubes with some traces of partially filled $\mathrm{Pt}-\mathrm{Cu}$ nano-octapods (Figure $3 \mathrm{a}$ ). Nevertheless, these tetrahedral seeds will have to maintain their morphology throughout, because the generation of an intermediate structure for the conversion between the nanotetrahedra to nanocubes may require much higher energy. In very rare cases, a minor constituent of multitwinned particles with a decahedral shape may be simultaneously generated from the nucleation. This type of seeds may result in the growth of nanorods with a fivefold twinned rod structure as discussed previously. ${ }^{[41,46-49]}$ The nucleation and even additional growth process are actually reasonably fast. Under present conditions, "crêpe-shaped" $\mathrm{Pt}-\mathrm{Cu}$ nanocubes can be generated in around 4 min (Figure $3 b$ ).

The catalytic activity of the $\mathrm{Pt}-\mathrm{Cu}$ nanocubes towards methanol oxidation was investigated. A cyclic voltammograms $(\mathrm{CVs})$ of these nanocubes in $0.1 \mathrm{M} \mathrm{HClO}_{4} / 1 \mathrm{M} \mathrm{MeOH}$ is shown in Figure 4 a. For comparison, results from experiments
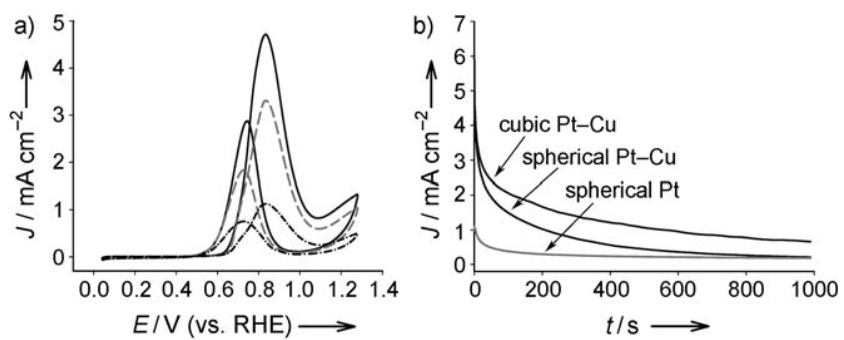

Figure 4. a) Cyclic voltammograms of $\mathrm{MeOH}$ oxidation on $\mathrm{Pt}-\mathrm{Cu}$ nanocubes $(-), \mathrm{Pt}-\mathrm{Cu}$ nanospheres $(--)$, and $\mathrm{Pt}$ nanospheres (---.) in $0.1 \mathrm{M} \mathrm{HClO}_{4} / 1 \mathrm{M} \mathrm{MeOH}$ (scan rate: $0.02 \mathrm{Vs}^{-1}$ ). The electrode potentials are reported versus a reversible hydrogen electrode (RHE). b) Chronoamperometric results of $\mathrm{MeOH}$ oxidation at $0.8 \mathrm{~V}$ on $\mathrm{Pt}-\mathrm{Cu}$ nanocubes, $\mathrm{Pt}-\mathrm{Cu}$ nanospheres, and $\mathrm{Pt}$ nanospheres in $0.1 \mathrm{M} \mathrm{HClO}_{4} /$ $1 \mathrm{M} \mathrm{MeOH}$.

with spherical $\mathrm{Pt}-\mathrm{Cu}$ and $\mathrm{Pt} \mathrm{NCs}$ of similar sizes are also included. The current density $(J)$ was calculated with respect to the Pt surface area measured from the hydrogen adsorption-desorption charges. The electrode potentials are reported versus a reversible hydrogen electrode (RHE). It is clear that the highest methanol oxidation current density was obtained with $\mathrm{Pt}-\mathrm{Cu}$ nanocubes. For example, the maximum peak value of methanol oxidation current density on $\mathrm{Pt}-\mathrm{Cu}$ nanocubes is $4.7 \mathrm{mAcm}^{-2}$, whereas that for the $\mathrm{Pt}$ NPs is $1.1 \mathrm{~mA} \mathrm{~cm}^{-2}$. The higher methanol oxidation current density on $\mathrm{Pt}-\mathrm{Cu}$ nanocubes was further confirmed by the chronoamperometric measurements performed at $0.8 \mathrm{~V}$ (Figure $4 \mathrm{~b})$. The catalytic activity follows the order $\mathrm{Pt}-\mathrm{Cu}$ nanocube $>\mathrm{Pt}-\mathrm{Cu}$ nanosphere $>\mathrm{Pt}$ nanosphere, with current-density values of $2.1,1.5$, and $0.4 \mathrm{~mA} \mathrm{~cm}^{-2}$, respectively, at $100 \mathrm{~s}$ and $0.8 \mathrm{~V}$. The same activity order was also observed at $0.6 \mathrm{~V}$, and the activity on $\mathrm{Pt}$ nanospheres is very similar to that of commercial Pt/C catalysts (Figure S6 in the Supporting Information). Interestingly, the methanol oxidation activity of 
$\mathrm{Pt}-\mathrm{Cu}$ nanospheres decreased over longer periods of time, and eventually reached the same level as that of the $\mathrm{Pt}$ nanospheres. These results apparently indicate that the $\{100\}$ confined $\mathrm{Pt}-\mathrm{Cu}$ nanocubes offer a higher electrocatalytic activity towards methanol oxidation than those with mixed crystallographic facets. The higher catalytic activity of $\mathrm{Pt}-\mathrm{Cu}$ nanocubes may be attributed to the electronic structure modification of $\mathrm{Pt}$ surface with the presence of $\mathrm{Cu}$, as commonly observed in transition-metal-Pt alloys. ${ }^{[50-52]}$

In conclusion, high-quality $\mathrm{Pt}-\mathrm{Cu}$ nanocubes were successfully prepared from a hot organic solution. All of the synthetic conditions, such as the OLA/TOAB ratio as well as the amounts of DDT and TDD, were fully optimized for the formation of $\mathrm{Pt}-\mathrm{Cu}$ nanocubes. The mechanism of nucleation and NC growth was explored and discussed based on observation of the intermediate NPs when partial reaction parameters were precisely tuned. The electrochemical catalytic activity of these $\mathrm{Pt}-\mathrm{Cu}$ nanocubes towards methanol oxidation was also evaluated in comparison with the activity of spherical Pt-Cu NCs and Pt NCs with similar sizes. The Pt$\mathrm{Cu}$ nanocubes demonstrated a superior electrocatalytic activity, which implies that the $\{100\}$-terminated $\mathrm{Pt}-\mathrm{Cu}$ nanocubes offer a higher activity towards methanol oxidation than those with mixed crystallographic facets.

\section{Experimental Section}

In a typical synthesis, $\left[\mathrm{Pt}(\mathrm{acac})_{2}\right] \quad(0.05 \mathrm{mmol}), \quad\left[\mathrm{Cu}(\mathrm{acac})_{2}\right]$ $(0.05 \mathrm{mmol})$, DDT $(0.5 \mathrm{mmol})$, and TOAB $(0.6 \mathrm{mmol})$ were mixed with ODE $(7.0 \mathrm{~mL})$ in a three-neck flask, and heated under vigorous agitation. With an increase in temperature, the reactants gradually dissolved, and the solution became clear at $80^{\circ} \mathrm{C}$. The mixture was then heated to $110^{\circ} \mathrm{C}$, and premixed OLA $(0.94 \mathrm{mmol})$ in ODE $(1.6 \mathrm{~mL})$ and prediluted DDT $(0.05 \mathrm{mmol})$ in ODE $(0.25 \mathrm{~mL})$ were then injected into the flask in sequence. The solution was subsequently heated to $230^{\circ} \mathrm{C}$ for $20 \mathrm{~min}$, quenched by quickly injecting toluene $(6 \mathrm{~mL})$ into the system, and cooled to room temperature without further agitation. Details of synthetic procedures and characterization are given in the Supporting Information.

Received: January 16, 2009

Revised: March 21, 2009

Published online: April 29, 2009

Keywords: alloys - copper - methanol electrooxidation . nanostructures $\cdot$ platinum

[1] R. Narayanan, M. A. El-Sayed, J. Phys. Chem. B 2003, 107, $12416-12424$.

[2] J. Zhang, M. B. Vukmirovic, Y. Xu, M. Mavrikakis, R. R. Adzic, Angew. Chem. 2005, 117, 2170-2173; Angew. Chem. Int. Ed. 2005, 44, 2132-2135.

[3] M. S. El-Deab, T. Ohsaka, Angew. Chem. 2006, 118, 6109-6112; Angew. Chem. Int. Ed. 2006, 45, 5963-5966.

[4] L. Pino, V. Recupero, S. Beninati, A. K. Shukla, M. S. Hegde, P. Bera, Appl. Catal. A 2002, 225, 63-75.

[5] A. T. Bell, Science 2003, 299, 1688-1691.

[6] A. Roucoux, J. Schulz, H. Patin, Chem. Rev. 2002, 102, $3757-$ 3778.

[7] K. R. Williams, G. T. Burstein, Catal. Today 1997, 38, 401-410.

[8] C. Wang, H. Daimon, Y. Lee, J. Kim, S. Sun, J. Am. Chem. Soc. 2007, 129, 6974-6975.
[9] R. Narayanan, M. A. El-Sayed, J. Am. Chem. Soc. 2004, 126, $7194-7195$.

[10] R. Narayanan, M. A. El-Sayed, Nano Lett. 2004, 4, 1343 -1348.

[11] N. Tian, Z.-Y. Zhou, S.-G. Sun, Y. Ding, Z. L. Wang, Science 2007, 316, 732-735.

[12] N. M. Markovic, H. A. Gasteiger, J. Philip, N. Ross, J. Phys. Chem. 1995, 99, 3411-3415.

[13] K. Kinoshita, J. Electrochem. Soc. 1990, 137, 845-848.

[14] C. Wang, H. Daimon, T. Onodera, T. Koda, S. Sun, Angew. Chem. 2008, 120, 3644-3647; Angew. Chem. Int. Ed. 2008, 47, $3588-3591$.

[15] H. Lee, S. E. Habas, S. Kweskin, D. Butcher, G. A. Somorjai, P. Yang, Angew. Chem. 2006, 118, 7988-7992; Angew. Chem. Int. Ed. 2006, 45, 7824-7828.

[16] H. Song, F. Kim, S. Connor, G. A. Somorjai, P. Yang, J. Phys. Chem. B 2005, 109, 188-193.

[17] T. S. Ahmadi, Z. L. Wang, T. C. Green, A. Henglein, M. A. ElSayed, Science 1996, 272, 1924-1925.

[18] J. Chen, T. Herricks, Y. Xia, Angew. Chem. 2005, 117, $2645-$ 2648; Angew. Chem. Int. Ed. 2005, 44, 2589-2592.

[19] X. Teng, H. Yang, Nano Lett. 2005, 5, 885-891.

[20] B. Mayers, X. Jiang, D. Sunderland, B. Cattle, Y. Xia, J. Am. Chem. Soc. 2003, 125, 13364-13365.

[21] J. Chen, T. Herricks, M. Geissler, Y. Xia, J. Am. Chem. Soc. 2004, 126, $10854-10855$.

[22] T. Jacob, W. A. Goddard III, J. Phys. Chem. B 2004, 108, 8311 8323.

[23] K.-W. Park, J.-H. Choi, B.-K. Kwon, S.-A. Lee, Y.-E. Sung, H.-Y. Ha, S.-A. Hong, H. Kim, A. Wieckowski, J. Phys. Chem. B 2002, 106, 1869-1877.

[24] U. A. Paulus, A. Wokaun, G. G. Scherer, T. J. Schmidt, V. Stamenkovic, N. M. Markovic, P. N. Ross, Electrochim. Acta 2002, 47, 3787-3798.

[25] Z. Liu, C. Yu, I. A. Rusakova, D. Huang, P. Strasser, Top Catal. 2008, 49, 241-250.

[26] H. A. Gasteiger, S. S. Kocha, B. Sompalli, F. T. Wagner, Appl. Catal. B 2005, 56, 9-35.

[27] V. R. Stamenkovic, B. S. Mun, M. Arenz, K. J. J. Mayrhofer, C. A. Lucas, G. Wang, P. N. Ross, N. M. Markovic, Nat. Mater. 2007, 6, 241-247.

[28] V. Stamenkovic, B. S. Mun, K. J. J. Mayrhofer, P. N. Ross, N. Markovic, J. Rossmeisl, J. Greeley, J. K. Nørskov, Angew. Chem. 2006, 118, 2963-2967; Angew. Chem. Int. Ed. 2006, 45, $2897-$ 2901.

[29] E. Arola, C. J. Barnes, R. S. Rao, A. Bansil, M. Pessa, Surf. Sci. 1991, 249, 281-288.

[30] N. Toshima, Y. Wangl, Langmuir 1994, 10, 4574-4580.

[31] T. Komatsu, A. Tamura, J. Catal. 2008, 258, 306-314.

[32] R. E. Schaak, A. K. Sra, B. M. Leonard, R. E. Cable, J. C. Bauer, Y.-F. Han, J. Means, W. Teizer, Y. Vasquez, E. S. Funck, J. Am. Chem. Soc. 2005, 127, 3506-3515.

[33] As detailed in the Supporting Information, the average molar ratio of $\mathrm{Pt} / \mathrm{Cu}$ is 0.598:0.402 $( \pm 0.018)$ on the basis of EDS (TEM) determination on five samples. The ICP-MS measurement supports this result, with an average molar ratio $(\mathrm{Pt} / \mathrm{Cu})$ of $0.64: 0.36( \pm 0.02)$. The average molar ratio of $\mathrm{Pt} / \mathrm{Cu}$ evaluated by using EDS (SEM) is also close to this composition.

[34] W. Lu, J. Fang, K. L. Stokes, J. Lin, J. Am. Chem. Soc. 2004, 126, $11798-11799$.

[35] A. Filankembo, S. Giorgio, I. Lisiecki, M. P. Pileni, J. Phys. Chem. B 2003, 107, 7492-7500.

[36] Y. Zhang, M. E. Grass, J. N. Kuhn, F. Tao, S. E. Habas, W. Huang, P. Yang, G. A. Somorjai, J. Am. Chem. Soc. 2008, 130, $7492-$ 7500.

[37] F.-R. Fan, D.-Y. Liu, Y.-F. Wu, S. Duan, Z.-X. Xie, Z.-Y. Jiang, Z.-Q. Tian, J. Am. Chem. Soc. 2008, 130, 6949-6951. 
[38] R. Romeo, G. Arena, L. M. Scolaro, M. R. Plutino, G. Bruno, F Nicolo, Inorg. Chem. 1994, 33, 4029-4037.

[39] S. Saita, S. Maenosono, Chem. Mater. 2005, 17, 6624-6634.

[40] C. B. Murray, C. R. Kagan, M. G. Bawendi, Annu. Rev. Mater. Sci. 2000, 30, 545-610.

[41] Y. Xiong, Y. Xia, Adv. Mater. 2007, 19, 3385-3391.

[42] J. Zhang, K. Sun, A. Kumbhar, J. Fang, J. Phys. Chem. C 2008, $112,5454-5458$

[43] Z. L. Wang, J. Phys. Chem. B 2000, 104, 1153-1175.

[44] J.-M. Zhang, F. Ma, K.-W. Xu, Appl. Surf. Sci. 2004, 229, 34-42.

[45] R. Belkhou, J. Thiele, C. Guillot, Surf. Sci. 1997, 377-379, $948-$ 952.
[46] J. L. Elechiguerra, J. Reyes-Gasga, M. J. Yacaman, J. Mater. Chem. 2006, 16, 3906-3919.

[47] H. Chen, Y. Gao, H. Zhang, L. Liu, H. Yu, H. Tian, S. Xie, J. Li, J. Phys. Chem. B 2004, 108, 12038-12043.

[48] C. Ni, P. A. Hassan, E. W. Kaler, Langmuir 2005, 21, 3334-3337.

[49] C. J. Johnson, E. Dujardin, S. A. Davis, C. J. Murphy, S. Mann, J. Mater. Chem. 2002, 12, 1765-1770.

[50] Y. Tong, H. S. Kim, P. K. Babu, P. Waszczuk, A. Wueckowski, E. Oldfield, J. Am. Chem. Soc. 2002, 124, 468-473.

[51] M. Watanabe, K. Tsurumi, T. Mizukami, T. Nakamura, P. Stonehart, J. Electrochem. Soc. 1994, 141, 2659-2668.

[52] E. Antolini, J. R. C. Salgado, E. R. Gonzalez, Appl. Catal. B 2006, 63, 137-149. 